Composites Research, 26(1), 1-6(2013), pISSN: 1598-6934 DOI: http://dx.doi.org/10.7234/kscm.2013.26.1.1

논문

CNT-폴리프로필렌 복합재료의 기계적 물성평가 및 전기 미세평가법을 이용한 손상감지

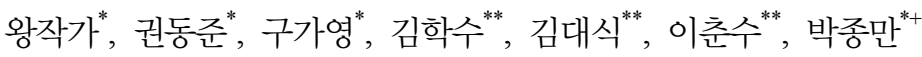

\title{
Evaluation of Mechanical Properties and Damage Sensing of CNT-Polypropylene Composites by Electro-Micromechanical Techniques
}

\author{
Zuo-Jia Wang*, Dong-Jun Kwon", Ga-Young Gu*, Hak-Soo Kim ${ }^{* *}$, \\ Dae-Sik Kim ${ }^{* *}$, Choon-Soo Lee ${ }^{* *}$, Joung-Man Park ${ }^{*+}$
}

\begin{abstract}
CNT-polypropylene (PP) composites were compounded by solvent dispersion method with uniform dispersion by using twin screw extruder. Damage sensing effects based on conductive carbon nanotubes (CNT) were evaluated to monitor the internal damage of CNT-PP composites using electrical resistance measurement. Mechanical and interfacial properties of CNT-PP composites were investigated and compared with neat PP. The mechanical properties of PP matrix were improved after adding CNT, because of the reinforcing effect of CNT fillers. In order to monitor the internal damage of CNT-PP composite, the change in electrical resistance of the composites was measured under fatigue loading and bending tests. CNT fillers exhibited good sensing under electrical resistance measurements. It is shown that CNT-PP composites with low CNT contents allow identifying critical cyclic loading, which are found to be accompanied with the internal failure.

\section{초 록}

용액 분산법을 이용하여 $\mathrm{CNT}$ 를 균질하게 분산시켰고, CNT-폴리프로필렌 복합재료 제조를 위해 압출기와 사출기를 사용하였다. $\mathrm{CNT}$ 고유의 전도성을 기반으로 CNT-PP 복합재료의 내부 손상을 감지하기 위해 전기저항 측정법을 이용하였다. CNT-PP의 기계적 및 계면 물성을 확인하고 일반 $\mathrm{PP}$ 와 비교하였다. CNT의 강화 효과로 인하여 CNT를 함유함으로서, PP 기지의 기계적 물성은 더 증가되는 경향을 확인하였다. CNT-PP 복합재료의 내부 손상을 평가하기 위해 파괴 및 굴곡실험을 진행하며, 동시에 발생되는 전기 저항 변화도를 감지하여 미세손상을 평가하였다. CNT 강화제의 첨가는 좋은감지능을 보여주었다. 낮은 CNT 함유율임에도 CNT-PP 복합재료의 감지가 가능했으며, 반복 하중 실험 중 최대 임계 응력을 확인하여, 내부에 발생된 미세 파괴를 찾아 낼 수 있었다.
\end{abstract}

Key Words : 계면(interface), 보강재(reinforcement), 피로 평가(fatigue test), 미세 손상(microcrack)

\footnotetext{
접수: 2012년 9월 11일, 수정: 2013년 2월 1일, 게재승인: 2012년 12월 15일

* 경상대학교 나노·신소재공학부 대학원

*+ 경상대학교 나노·신소재공학부, 공학연구원, Corresponding author(E-mail:jmpark@gnu.ac.kr)

** 현대자동차, 고분자재료연구팀
} 
높은 강직성, 낮은 비중, 메틸기에 의한 내안정성을 가지고 있는 점이 장점이다. 성형이 용이하고 기계적 물성 역시 안 정적인 장점을 가진다[1].

최근 나노크기의 입자를 강화제로 사용하는 경우가 크게 증가하였다. 이는 높은 형상비에 의한 강화 효과와 나노크기 의 입자사이즈에 의한 소량으로도 대면적 분산이 가능하기 때문이다[2]. 탄소나노튜브(carbon nanotubes, CNTs)는 전기 전도성을 가진다는 점에서 가장 큰 장점이 다. 나노복합재료 를 제조할 때, 전도성을 이용하여 고분자를 부도체에서 도체 로 만들기 때문이다. 강화제로의 CNT 효과는 고분자 기지 내부에 전기전도성 뿐만 아니라 강화제로의 응력완화 기능을 하기 때문에 많은 분야에서 이용 된다[3]. 그러나, 고분자기 지 내부에 $\mathrm{CNT}$ 분산을 균일하게 하는 것은 쉬운 일이 아니 다. CNT 나노입자의 반데르발스 힘에 의한 반발력으로 입자 간 엉킴이 발생되기 때문이다. 제대로 $\mathrm{CNT}$ 를 고분자기지에 분산시키려면 특별한 조건이 필요하다. 균질한 분산결과를 확보할 수 있다면 탄소섬유의 활용과 같이 강화제로의 응용 성은 매우 높아질 것이다[4].

산업계에서 열가소성 고분자 복합재료를 활용하려는 움직 임이 매우 크게 성장하고 있다. 이는 기존의 열가소성 고분 자 재료가 비중이 낮아 차량 및 항공용 소재로 활용될 경우 연비를 줄일 수 있기 때문이다. 열가소성 고분자 기지에 강 화제로 $\mathrm{CNT}$ 를 접목 시키려고 하고 있다. 이는 높은 형상비 를 이용하여 소량으로도 고강도 제품을 제조하여, 기계적 물 성 뿐 아니라 경제적 효과를 얻기 위해 다양한 열가소성 고 분자 나노복합재료에 대한 응용이 대두될 것이다[5].

재료를 사용하는 기간 동안 고분자 기지는 미세한 균열이 발생되며 미세 균열을 장기간 방치할 경우 큰 균열 및 파괴 로 발전 될 수 있다. 때문에 이러한 미세 균열을 미리 감지 하고 평가하는 것이 중요한 연구 분야이다. 손상 감지를 위 해서 구조적인 해석과 그에 따름 관찰을 명확하게 정리하고, 명료하게 평가하는 방법을 확보하는 것이 중요하다[6]. CNT 의 전도성을 이용한 자체 감지능을 가진 나노복합재료 내부 의 미세 손상감지가 가능하다. 일반적으로 전기저항 측정법 을 이용해서 손상감지를 시도 하면 여러 차원에서의 기지 재 료에 대한 내부 손상을 감지할 수 있다[7]. 고분자 기지내부 에서의 $\mathrm{CNT}$ 입자간 네트위크에 따라 전기적 신호의 흐름이 생성된다. 응력에 의해 일정 구간의 손상이 발생될 경우 CNT 네트워크의 변화가 발생된다. 구조적으로 변화가 생길 때 전기적 신호의 변화를 감지할 수 있게 된다. 이러한 원리 를 이용하여 내부 손상 감지에 대한 적용이 나노복합재료에 가능한 것이다[8].

본 연구에서는 낮은 농도의 CNT를 이용함으로써 PP 기 지 자체의 센싱이 가능하도록 나노복합재료를 제조하였다. CNT-PP 나노복합재료의 기계적 물성을 평가하고 CNT와 PP 간의 계면 물성을 기본적으로 평가하였다. 또한 내부 손상 감지 정도를 평가하기 위해 파괴 및 굴곡 평가를 반복하중실
험으로 진행하였다. 이때 전기저항 측정법을 이용한 전기저 항변화도를 확인하여 CNT-PP의 미세 손상 여부를 확인하였 다. 전기저항 측정법을 이용한 내부 손상 감지 평가방법에 대한 고찰을 시도할 수 있었다.

\section{2. 실 험}

\section{1 재료}

직경이 10-25 nm 다중벽 탄소나노튜브(CNT) (MW-CNT, 일 진나노텍, 한국)을 자체-센서 소재 및 강화제로 사용하였다. PP (M1400, LG 화학)를 이용하여 나노복합재료 기지로 활용하였 다. 자일렌(Samchun Pure Chemical Co.)을 사용하여 용액 분산 법으로 CNT를 분산시켰고, 유리섬유(RS2200KT-111A, Owens Corning (주), 미국) 평균 $16 \mu \mathrm{m}$ 를 사용하여 강화 섬유로 이용 하였다.

\section{2 방법}

\subsubsection{CNT-PP 나노복합재료의 제조}

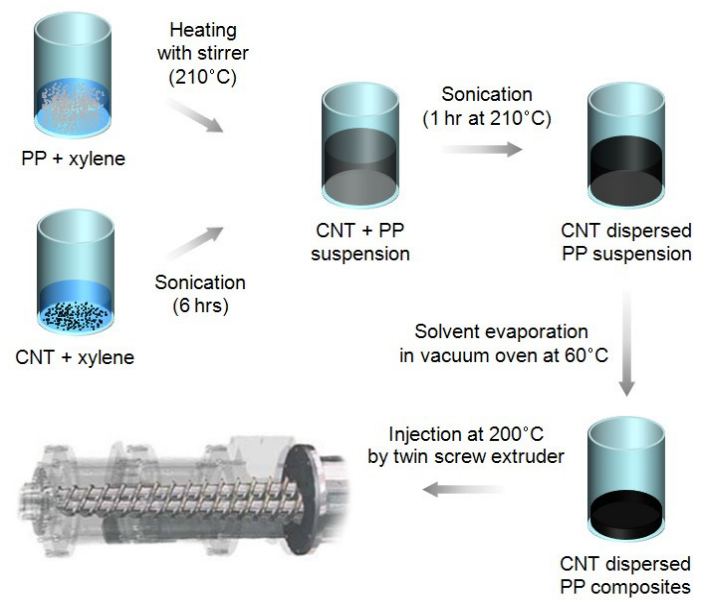

Fig. 1 Schematic for the fabrication process of CNT-PP composites.

Fig. 1은 CNT-PP를 제조하는 성형과정을 나타낸 그림이 다. 복합재료의 시편을 제조하기 위해서는 두 가지 공정을 이용하여 성형하였다. 나노입자를 분산시키는 과정과 인젝션 몰딩 시키는 과정을 거친다. 일반적으로, 재료의 물성을 평가 하기 위해 인장과 굴곡 시편을 제조하였다. CNT의 함량은 소량으로 설정하여 $0.5 \mathrm{wt} \%$ 로 정하였다. 분산 과정에서는 자 일렌을 이용하여 용액 존재 하에서 CNT를 PP 파우더와 함 께 소니케이션 및 교반과정을 거쳤다. Fig. 1 의 (1) 단계에서 $210^{\circ} \mathrm{C}$ 온도 하에서의 교반 작용을 진행하며 $\mathrm{PP}$ 와 자일렌을 교반한다. 이후 $\mathrm{CNT}$ 와 $\mathrm{pp}$ 가 분산된 용액을 이용하여 균일한 $\mathrm{CNT}$ 분산 상태를 얻기 위한 사전 단계를 거친다. (2) 제조 
된 두 용액을 1 시간 동안 소니케이션 혼합 과정을 거친다. (3) 분산을 시키기 위해 사용하였던 자일렌을 제거하기 위해 24 시간 동안 $60^{\circ} \mathrm{C}$ 온도 하에서 진공 오븐으로 건조를 시킨 다. 건조되어 용매가 제거된 CNT-PP 파우더를 이용하여 혼 합 과정을 가지고 인젝션 몰딩을 통해 시편을 제조한다. 압 출기(Bau-Tech, Korea)를 이용하였다. 스크롤의 직경은 $19 \mathrm{~mm}$ 이고 두 스크롤 간의 사이는 $18.4 \mathrm{~mm}$ 이다. $\mathrm{L} / \mathrm{D}$ 정도는 40 으 로 하였다. 스크롤 속도는 $150 \mathrm{rpm}$ 으로 성정하였으며 시편 을 제조하기 위해 사출기를 이용하였을 경우 사출기의 단계 별 온도 조건은 $190 / 190 / 200 / 200^{\circ} \mathrm{C}$ 로 하였다.

\subsection{2. 기계적 물성 평가}

기계적 물성을 평가하기 위해 기본적으로 인장실험을 하였다. $\mathrm{UTM}(\mathrm{LR} 10 \mathrm{~K}$, Lloyd 사,영국)을 이용하고, 실험의 기준은 ASTM D638을 기준으로 하였다. 인장 속도는 $50 \mathrm{~mm} / \mathrm{min}$ 으로, 시편의 규격은 $33 \times 6 \times 3 \mathrm{~mm}$ 로 설정하였다.

두 번째로 아이조드 충격 실험을 하였다. 해머의 에너지는 $6.8 \mathrm{~J}$ 이며 $3.5 \mathrm{~m} / \mathrm{s}$ 의 속도로 운동하였다. 시편 규격은 $63 \times$ $12.7 \times 3 \mathrm{~mm}$ 로 설정하였다. 10 번의 반복 실험을 통해 실험 결과를 통계적으로 정리하였다.

2.2.3 분산도 평가

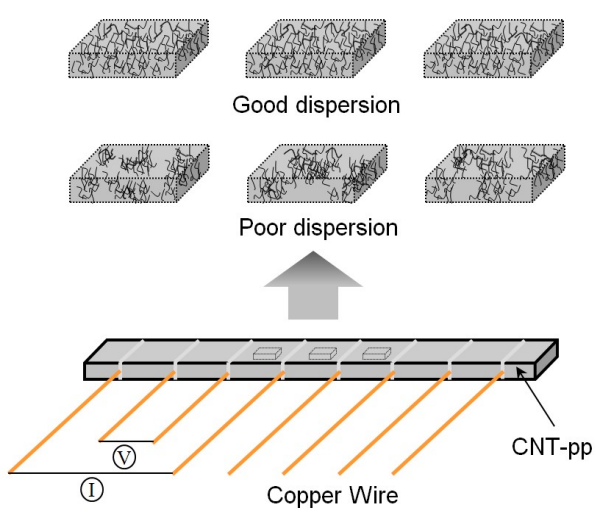

Fig. 2 Schematic sketch of the volumetric resistivity test specimen.

4 단자법을 이용하여 CNT-PP의 전기저항을 측정하였다. 멀티미터(HP34401A, Agilent, 미국)를 이용하여 전반적인 실 험을 진행하였다. 실험 시편에 대한 모식도는 Fig. 2와 같다. 시편의 전기저항을 측정하기 위해 시편 내부에 구리선을 삽 입하였으며, 접촉저항을 줄이기 위해서 은 페인트를 사용하 였다. 측정된 전기저항 결과를 이용하여 재료의 부피 저항을 측정하였다. 부피저항 관련 수식은 다음 같다.

$$
\rho_{v}=\left(\frac{A_{v}}{L_{e c}}\right) \times R_{v}(\Omega \cdot \mathrm{cm})
$$

여기서, $\rho_{v}$ 는 전기전도도, $R_{v}$ 는 측정되는 전기저항의 결과, $A_{v}$ 는 접촉되는 면적이며, $L_{e c}$ 는 시편내부에서의 측정 거리에 대한 인자이다.

표면의 조성을 확인하기 위해 전자 주사현미경(Field emission 전자현미경, FE-SEM. Philips XL30 S FEG, 네델란드)를 이용 하여 만 배로 확대하여 인장 실험 후 파괴된 시편의 파단면을 관찰하였다.

\subsection{4 계면접착력 평가}

계면 전단강도(interfacial shear strength, IFSS)를 측정하기 위해서 유리섬유를 이용하였다. 유리섬유와 CNT-PP 복합재 료 간의 계면 물성을 마이크로드롭렛 풀아웃 실험을 통해 비 교하였다. 섬유 한 가닥에 CNT-PP 기지를 함침 시키기 위해 녹이는 과정을 거쳐 시편을 확보하였다. 실험에 대한 결과는 마이크로드랍 크기의 수지가 섬유에서 풀아웃 될 경우 발생 되는 힘을 측정하여 계면 강도를 측정하는 원리이다[9]. 이때 발생되는 풀아웃 힘 $\mathrm{F}$ 을 이용하여 계면전단강도를 측정할 수 있으며 아래의 식을 이용하여 계산할 수 있다.

$$
\tau=\frac{F}{\pi D_{f} L}
$$

$D_{f}$ 과 $L$ 는 섬유의 직경과 섬유의 표면에 함침 되어진 수지 에 대한 직경과 길이 에 대한 인자이다.

\subsection{5 파괴 실험 및 굴곡 실험}

미세 파괴에 대한 규명을 위해 필요한 실험으로 파괴 실 험을 진행하였다. 이때 발생되는 응력이 미세 균열을 일으키 는 인자가 된다. 파괴 실험을 반복하중의 조건하에서 실험하 였다. 이동 신율을 $4 \%$ 로 하고, 실험을 하였다. 이때의 발생 힘과 전기저항 변화도에 대한 결과를 정리하여 파괴 실험 결 과를 정리하였다. 시편의 규격은 $25 \mathrm{~mm}$ 의 길이에, $5 \mathrm{~mm}$ 의 폭, $2 \mathrm{~mm}$ 의 두께를 가진 시편을 이용하였다.

다른 평가방법으로 3 포인트 실험을 이용한 굴곡 실험을 진행하였다. $60 \mathrm{~mm}$ 의 길이에, $10 \mathrm{~mm}$ 의 폭에, $3 \mathrm{~mm}$ 의 두께 를 지닌 시편을 이용하였다. 이 실험 역시 반복 피로 실험을 진행하면서 전기저항 변화도를 파악하였다.

\section{3. 결과 및 토론}

\subsection{CNT-PP의 기계적 물성 평가}

Fig. 3은 일반 PP와 CNT-PP의 인장 물성을 비교 평가한 결과이다. 이 결과를 통해 인장 강성도는 증가한 반면 인장 강도는 큰 변화가 없었다. 낮은 CNT 농도에서 복합재료의 시편 내부에서의 응력 전달을 완화시켰으며 그에 따른 강성 도의 증가로 $\mathrm{CNT}$ 의 강화효과를 확인하였다. 


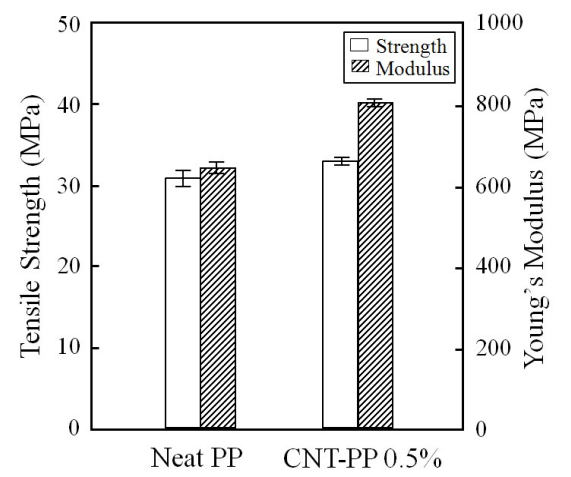

Fig. 3 Tensile test results for neat PP and CNT-PP composites.

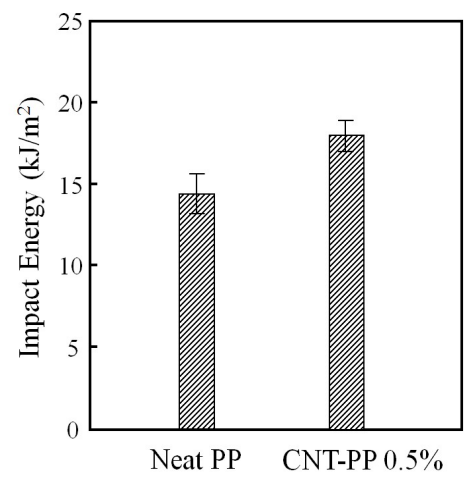

Fig. 4 Izod impact test results for neat PP and CNT-PP composites.

Fig. 4는 아이조드 실험의 결과이며, 역시 CNT의 유무에 의해 강도 차이가 발생됨을 확인하였다. CNT의 강화제 효과 가 PP 내부에서 crack pinning 효과를 발휘하여 충격에 의한 파괴를 최소화 시키고 기존의 재료 물성보다 높은 강도를 지 니도록 나노복합재료화된 물성으로 개질되었기 때문이다.

\subsection{PP 내의 CNT 분산도 평가}

Fig. 2의 부피저항측정 시편을 이용하여 CNT-PP 나노복 합재료 내부의 $\mathrm{CNT}$ 의 분산 상태를 확인하였다. 부피저항 측 정은 4 단자법을 이용해서 측정하였으며 그에 따른 결과로 $\mathrm{CNT}$ 입자의 고른 분산 상태를 확인 할 수 있었다. 5 개의 구 간을 확인하여 부피저항을 측정하였을 때, 구간별 부피저항 결과는 $6.7,6.3,6.7,6.6,6.9 \mathrm{M} \Omega$ 로 매우 일정한 구간별 결 과를 확인하였다. 전반적으로 높은 전기저항의 결과는 낮은 $\mathrm{CNT}$ 함량 때문이나, 균질한 분산 상태에 의해 5 개의 구간별 일정한 부피저항 결과를 얻을 수 있었다.

Fig. 5는 FE-SEM 촬영 결과이다. 일반 $\mathrm{PP}$ 와 $0.5 \mathrm{wt} \%$ CNT-PP 나노복합재료의 파단면의 사진이다. 사진에서 확인 되듯이 CNT-PP 나노복합재료의 표면은 $\mathrm{CNT}$ 의 분산 결과에
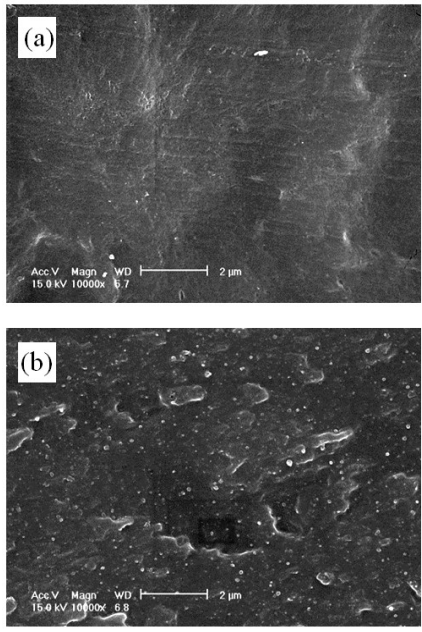

Fig. 5 Fracture surfaces for: (a) neat PP; (b) CNT-PP composites.

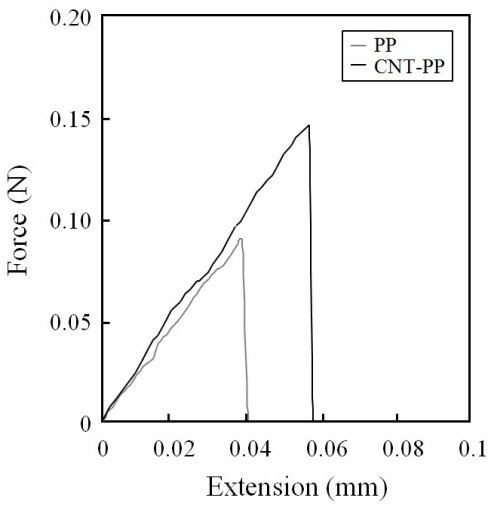

Fig. 6 Microdroplet pull-out test results for a glass fiber embedded in neat PP and CNT-PP composites.

의해서 일반 PP에 비해 거친 표면을 확인하였다. CNT의 조 성이 표면에 확인되는 결과를 통해 $\mathrm{CNT}$ 의 응력 완화 역할에 의해 기존 $\mathrm{PP}$ 의 물성보다 강화된 물성을 비교할 수 있었다.

\section{3 유리섬유와 CNT-PP 나노복합재료의 계면 접착} 력 평가

Fig. 6은 마이크로드랍렛 풀아웃 실험법을 통해 유리섬유와 일반 PP 또는 CNT-PP의 두 기지의 풀아웃 힘 차이를 비교 하였다. 섬유 표면에 함침 된 마이크로드랍의 직경은 $300 \mu \mathrm{m}$ 로 제조하였다. 풀아웃 실험을 진행하면서 비교하는 수치는 풀아웃 될 때 발생되는 힘 값을 이용하여 결과를 비교했다. CNT-PP의 풀아웃 힘이 일반 $\mathrm{PP}$ 이 비해 힘이 더 증가되는 결과를 확인 하였다. 수지와 섬유간의 계면 접착력을 평가하면, 일반 $\mathrm{PP}$ 수지와 섬유간의 IFSS 결과는 $9.1 \mathrm{MPa}$ 였으나, $\mathrm{CNT}$ 를 함유한 수지일 경우 $15.6 \mathrm{MPa}$ 결과를 얻었다. 이는 CNT-PP의 경우 


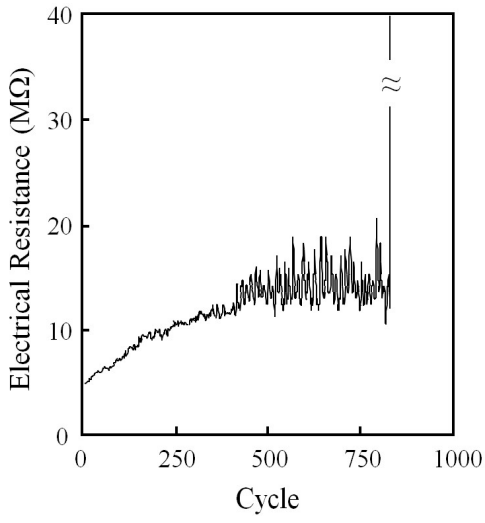

Fig. 7 Load and electrical resistance change for a CNT-PP composite in a fatigue test.

일반 PP에 비해 향상된 표면 거칠기의 영향 및 CNT-PP의 강화효과가 수지적인 측면에서 기본 물성이 증가된 점, $\mathrm{CNT}$ 의 미세 계면간의 접착면 향상들을 원인을 들 수 있다.

\subsection{CNT-PP 복합재료의 손상 감지}

Fig. 7은 CNT-PP 나노복합재료의 반복 피로 실험을 진행 한 실험 결과다. 인장 압축의 왕복 신율에 대해서 $4 \%$ 로 설 정하여 실험 했으며 진동 속도는 $1 \mathrm{~Hz}$ 의 속도로 실험하였 다. 기계적인 물성 평가에 따른 응력에 대한 결과와 전기저 항 측정 결과에 대해서 정리를 하였다. 초기 단계에 비해 전 기저항에 대한 결과가 서서히 증가되었으며 400회 사이클 단계에서 전기저항 그래프의 결과가 변화 되었다. 반복하중 에 의해 응력만 변화되는 것이 아니라 전기저항의 결과도 사 이클과 같이 변화되었다. 이는 반복 인장, 압축에 따라 내부 에 미세 크랙의 발생이 전기저항 변화를 발생시킨다. 미세 크랙이 발생됨으로써 인장 단계에서 미세 크랙은 더 크게 벌 어지고 이때의 전기저항은 기존보다 크게 증가된다. 하지만 압축 단계에서 미세 크랙의 접촉으로 초기 전기저항 결과와 유사하게 값이 감소된다. 특히 800 회의 사이클 이후에는 높 은 전기저항의 변화를 확인하였다. 이는 미세 크랙의 미세한 균열 성장에 의해서 기존의 균열 보다 증가됨을 의미한다.

Fig. 8은 3 포인트 굴곡 실험을 통해 확인한 CNT-PP 나 노복합재료의 실험 결과이다. 이 실험 결과 역시, Fig. 7과 비슷한 결과가 확인된다. 실험 초기에는 하중에 따라 재료가 응력을 받음으로써 서서히 저항 변화도가 증가되었다. 하지 만 약 80 사이클의 반복 하중의 결과로, 큰 폭의 전기저항 변화도 사이클을 확인하였다. 이는 미세 균열에 의한 영향이 다. 반복 하중에 의해 미세 균열 부분의 접촉과 미접촉 과정 의 반복이 전기저항 결과를 야기한다. 이런 결과들을 통해 $\mathrm{CNT}$ 를 함유한 $\mathrm{PP}$ 의 경우 전기저항 측정법을 이용하여 미세 균열 여부를 파악 가능하였다.

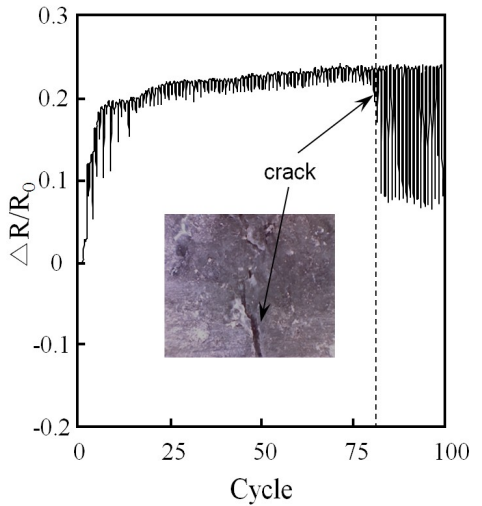

Fig. 8 Load and electrical resistance change for a CNT-PP composite during a bending test.

\section{4. 결 론}

CNT-PP 나노복합재료에 대한 제조방법에서부터 미세 손 상 감지 평가법에 대한 기초 연구를 확인하였다. 열가소성 플라스틱 내부에 $\mathrm{CNT}$ 를 고르게 분산시키기 위해 자일렌을 이용한 용액 분산법을 사용하였다. 용액 분산법을 이용한 분 산 결과에 대해서 전기저항 평가법을 이용하여, PP 기지 내 $\mathrm{CNT}$ 의 분산 상태가 균질한 결과를 확인하였다. 또한 $0.5 \%$ 의 낮은 $\mathrm{CNT}$ 함량에도 $\mathrm{PP}$ 의 인장, 충격 강도가 강화되는 결과를 확인하였다. 마이크로드랍렛 풀아웃 실험을 통해 IFSS 확인 결과 역시 일반 PP에 비해 CNT-PP 나노복합재료 가 유리섬유와의 계면 접착력 높았다. 유리섬유와의 계면 접 착력이 향상되는 이유는 CNT에 의한 미세 계면 생성과 그 에 따른 계면 접착력의 향상, CNT-PP의 거친 표면에 대한 계면접착력 향상 때문이다. 미세 손상 감지에 대해 확인하기 위해, 전기저항을 측정하면서 CNT-PP 복합재료의 파괴 및 굴곡 실험을 서 실험을 진행하였다. 동적 피로 실험에 따른 미세 균열의 발생의 여부를 전기저항 측정 결과로 확인 할 수 있었다. 동적 피로에 따른 재료 내부 미세 균열 부위에서 의 파단면간 접촉과 미접촉 현상에 따라 전기저항측정 결과 의 변화가 존재하였다. CNT의 전도성을 CNT-PP 복합재료의 센싱력을 이용하여 전기저항 측정법을 통해 미세 균열 손상 여부를 감지할 수 있었다.

\section{감사의 글}

이 연구는 현대자동차 그룹의 산학협동 미래과제의 지원을 받아 수행하였습니다. 본 연구자 중 왕작가은 2단계 $\mathrm{BK} 21$ 의 지원에 감사드립니다. 


\section{참고문헌}

1) Mi, Y., Chen, X., and Guo, Q.,"Bamboo fiber-reinforced polypropylene composites: crystallization and interfacial morphology," Journal of Applied Polymer Science, Vol. 64, No. 7 1997, pp. 1267-1273.

2) Lo'pez Manchado, M.A., Valentini, L., Biagiotti, J., and Kenny, J.M.,"Thermal and mechanical properties of singlewalled carbon nanotubes-polypropylene composites prepared by melt processing,"Carbon, Vol. 43, No. 7, 2005, pp. 1499-1505.

3) Naik, N.K., and Meduri, S.,"Polymer matrix composites subjected to low velocity impact : effect of laminate configuration,"Composites Science and Technology, Vol. 61, No. 10, 2001, pp. 1429-1436.

4) Ma, P.C., Siddiqui, N.A., Marom, G., and Kim, J.K., "Dispersion and functionalization of carbon nanotubes for polymer-based nanocomposites: a review," Composites: Part A, Vol. 41, No. 10, 2010, pp. 1345-1367.

5) Valentini, L., Biagiotti, J., Kenny, J.M., and Santucci, S.,"Morphological characterization of single-wall carbon nanotube/polypropylene composites," Composites Science and Technology, Vol. 63, 2003, pp. 1149-1153.

6) Gao, L., Thostenson, E.T., Zhang, Z., and Chou, T.W., "Coupled carbon nanotube network and acoustic emission monitoring for sensing of damage development in composites," Carbon, Vol. 47, No. 5, 2009, pp. 1381-1388.

7) Wang, X.J., and Chung, D.D.L.,"Real-time monitoring of fatigue damage and dynamic strain in carbon fiber polymermatrix composite by electrical resistance measurement," Smart Materials and Structures, Vol. 6, No. 4, 1997, pp. 504-508.

8) Boger, L., Wichmann, M.H.G., Meyer, L.O., and Schulte K., "Load and health monitoring in glass fibre reinforced composites with an electrically conductive nanocomposite epoxy matrix," Composites Science and Technology, Vol. 68, No. 7-8, 2008, pp. 1886-1894.

9) Kwon, D.J., Wang, Z.J., Gu, G.Y., Um, M.G., and Park, J.M., "Inherent And Interfacial Evaluation Of Fibers/Epoxy Composites By Micromechanical Tests At Cryogenic Temperature," Journal of the Korean Society for Composite Materials, Vol. 24, No. 4, 2011, pp. 11-16. 